\title{
Exkursion der Württembergischen Bibliotheksgesellschaft an den Bodensee
}

Am Samstag, dem 13. April 2013, starteten 15 Mitglieder der WBG in einem Kleinbus der Firma Binder zu einem Ausflug nach Biberach und Friedrichshafen.

Das erste Ziel war die Ausstellung "Christoph Martin Wieland - der Voltaire der Deutschen“ im Stadtmuseum Biberach anlässlich seines 200. Todestages. Claus Wilhelm Hoffmann, Oberbürgermeister von Biberach a.D. und Sohn unseres ehemaligen Direktors Wilhelm Hoffmann, hieß uns in dem herrlichen Innenhof willkommen.
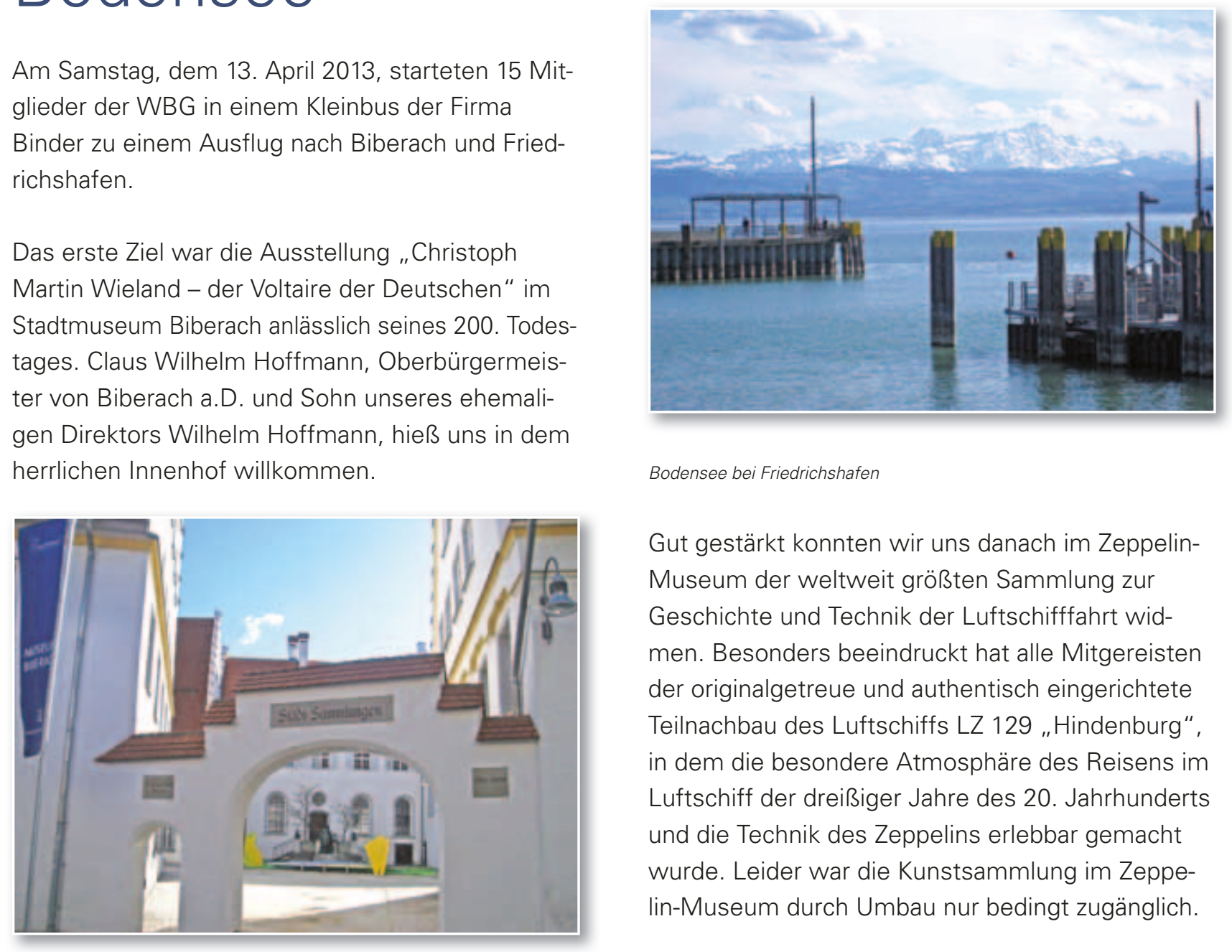

Bodensee bei Friedrichshafen

Gut gestärkt konnten wir uns danach im ZeppelinMuseum der weltweit größten Sammlung zur Geschichte und Technik der Luftschifffahrt widmen. Besonders beeindruckt hat alle Mitgereisten der originalgetreue und authentisch eingerichtete Teilnachbau des Luftschiffs LZ 129 "Hindenburg", in dem die besondere Atmosphäre des Reisens im Luftschiff der dreißiger Jahre des 20. Jahrhunderts und die Technik des Zeppelins erlebbar gemacht wurde. Leider war die Kunstsammlung im Zeppelin-Museum durch Umbau nur bedingt zugänglich.

Stadtmuseum Biberach

Bei der Führung im Stadtmuseum brachte uns Frau Moll sehr anschaulich das Leben und literarische Werk von Christoph Martin Wieland nahe.

Anschließend fuhren wir nach Friedrichshafen weiter. Nach einem kurzen Regenschauer während der Fahrt begrüßten uns ein wolkenloser Himmel und strahlender Sonnenschein am Bodensee.

Im Restaurant des Zeppelin-Museums waren Plätze reserviert, und so genossen wir schon während des Mittagessens das wunderbare Panorama der Schweizer Alpen.

Bei einem kurzen Bummel über die Seepromenade mit einem Eis in der Hand konnten wir die vielen Eindrücke des Tages noch auf uns wirken lassen, bevor wir uns vom Bodensee verabschieden mussten.

Verena Höser

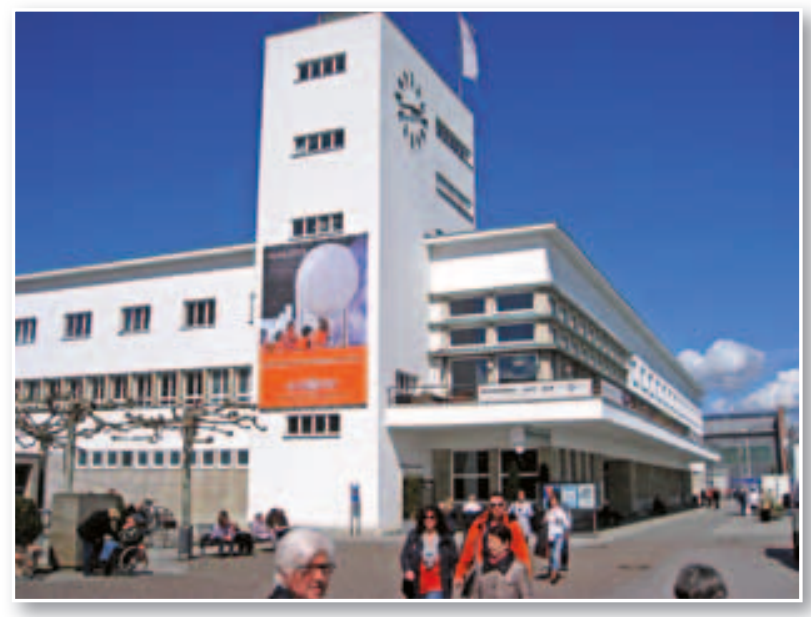

